\title{
A PRODUÇÃO CIENTÍFICA EM PERIÓdICOS INSTITUCIONAIS: UM ESTUDO DA REVISTA BIBLOS
}

\author{
João Paulo Borges Silveira ${ }^{\mathrm{i}}$
}

\begin{abstract}
Resumo: O presente artigo aborda a comunicação científica através da produção científica em periódicos institucionais, tendo por base um estudo da revista Biblos, periódico vinculado ao Instituto de Ciências Humanas e da Informação (ICHI) da Universidade Federal do Rio Grande (FURG). Para a pesquisa delimitou-se o período de circulação da revista entre 1978 e 2009, 31 anos de atividade, correspondendo a 32 fascículos e 392 artigos publicados. A pesquisa teve por objetivos traçar o perfil dos autores que publicaram artigos na referida revista e identificar as temáticas dos artigos publicados, seguindo as áreas do conhecimento estipuladas. O procedimento metodológico empregado foi a bibliometria, e a partir de seus resultados, os mesmos foram analisados sob um viés quantitativo e qualitativo. Dentre os resultados da pesquisa identificou-se que os autores com título de doutorado são maioria na revista, assim como os pesquisadores vinculados a FURG, sendo os autores com maior produtividade na revista são do quadro de docentes da universidade. Entre as áreas temáticas dos artigos, a História possui maioria absoluta de artigos publicados, com $67 \%$ do total, seguida da área das Ciências Sociais Aplicadas I, no qual se enquadra a área da Ciência da Informação.
\end{abstract}

Palavras-chave: Comunicação Científica. Produção Científica. Revista Biblos.

\section{THE SCIENTIFIC PRODUCTION IN PERIODIC INSTITUCIONAL: STUDY OF THE JOURNAL BIBLOS}

\begin{abstract}
This article discusses the scientific communication through scientific journals institutional, based on a study of Journal Biblos, journal linked to the Institute of the Humanities Sciences and the Information (ICHI), Federal University of the Rio Grande (FURG). To search delimit the period of circulation the magazine between 1978 and 2009, 31 years of activity, accounting for 32 fascicles and 392 articles published. The research aimed to define the profile of authors who published articles in the magazine and to identify the themes of articles published, following the knowledge areas stipulated. The methodological procedure used was bibliometrics, and from their results, they were analyzed under a bias quantitatively and qualitatively. Among the survey results identified that the authors are most doctorate by the magazine as well as there searchers linked FURG, although the authors with higher productivity in the magazine are part of the university teachers'. Among the topics of articles, History has an absolute majority of published papers with $67 \%$ of the total, followed by Applied Social Sciences I, which fits the area of information Science.
\end{abstract}

Key-words: Scientific Communication. Scientific Production. Jounal Biblos.

\footnotetext{
${ }^{\mathrm{i}}$ Universidade Federal de Pelotas. joao-pbs@hotmail.com. Recebido em:14/11/2011; aceito para publicação em: 12/02/2012.
} 


\section{INTRODUÇÃO}

As universidades em sua gênese, primam o ensino, a pesquisa e a extensão, o tripé da educação de nível superior no Brasil. Esses três quesitos básicos para a consolidação de destas instituições são essenciais para a formação dos graduandos para o mercado de trabalho, assim como para configuração e as transformações da sociedade. As universidades possuem importante papel social, político, econômico e cultural, pois são responsáveis pela formação dos chamados "futuros da nação".

O desenvolvimento de pesquisas nas universidades, permite que se desenvolva e melhore programas de avaliação no ensino nas mesmas. Esses resultados de pesquisa alcançam seus públicos de duas formas, com a extensão universitária (sendo o público alvo as comunidades ao redor da universidade através de ações que visam o desenvolvimento social) e pela comunicação da produção científica (tendo a comunidade científica e seus membros como público alvo). A produção científica é temática desta pesquisa, que nos remete à comunicação científica e aos estudos métricos da informação.

A presente pesquisa realizou um estudo bibliométrico da produção científica do periódico institucional das áreas de Ciências Humanas e Ciência da Informação da Universidade Federal do Rio Grande (FURG). De caráter descritivo e de temporalidade transversal, a pesquisa se coloca como uma opção de avaliação da produção de conhecimento científico proporcionado pela Revista do Departamento de Biblioteconomia e História e pela Biblos: revista do Departamento de Biblioteconomia e História.

A Revista do Departamento de Biblioteconomia e História da FURG surge em 1978 como uma alternativa de comunicação das pesquisas dos professores da instituição, estendendo-se até 1983, quando passa a se denominar Biblos: revista do Departamento de Biblioteconomia e História, permanecendo com esse título de 1985 a 2009. Apesar de ter havido mudança na nomenclatura do periódico e no seu registro (International Standard Serial Number - ISSN), manteve-se, à época, o mesmo corpo editorial, departamento responsável, foco e escopo editorial. Tendo em vista não haver prejuízos para a análise dos dados e desenvolvimento do trabalho, optou-se para essa pesquisa, denominar ambas as publicações com o mesmo nome, Biblos.

A análise da pesquisa compreendeu 31 anos de publicações de ambas revistas das áreas de Ciências Humanas e Ciência da Informação da FURG, de 1978 a 2009, perfazendo 32 fascículos, com periodização irregular, totalizando 392 artigos sub divididos por áreas do 
conhecimento e com 496 autorias. A pesquisa teve por objetivos traçar o perfil dos autores segundo suas publicações, analisando aspectos como sexo, titulação e instituição proveniente, e identificar as grandes áreas de pesquisa e temáticas dos artigos publicados.

A pesquisa se justifica por relatar à comunidade acadêmica como tem sido a produção científica nas áreas de Ciências Humanas e Ciência da Informação, mais propriamente da área de História e Biblioteconomia, a partir dos fascículos analisados. Assim como as áreas que as acompanham, a partir do sistema Qualis da revista Biblos, de acordo com a Coordenação de Aperfeiçoamento de Pessoal de Nível Superior (CAPES).

A coleta e análise dos dados levantados da revista Biblos, auxiliará na divulgação da importância de periódicos científicos institucionais na comunicação formal de pesquisas. Tendo como justificativa social à disseminação da produção científica, seja no formato impresso ou digital e a avaliação de parte da produção intelectual da FURG nas áreas das Ciências Humanas e Ciência da Informação, compreendidas pela Biblos, pois como afirma Araújo:

[...] o uso de dados bibliométricos como indicadores da produção científica passou a ser cada vez mais freqüente, diante do conjunto de ações que vêm sendo desenvolvidas no sentido de dispor desses indicadores para o planejamento nacional das atividades de pesquisa científica $(2006$, p. 26).

Outro ponto importante é que a Revista Biblos, no ano de 2010 passou por outra transformação, tendo a Ciência da Informação como área principal, denominando-se então de Biblos: revista do Instituto de Ciências Humanas e da Informação, segundo o site da revista, sendo que a área de História na universidade criou a Revista Historiae, que teve seus dois primeiros fascículos publicados no ano de 2010. No sentido profissional, a pesquisa se justifica pela possibilidade de ser um tema de interesse coletivo, tanto do corpo docente das áreas de Biblioteconomia e História, dos autores que tiveram seus artigos publicados, assim como à própria universidade e à comunidade científica em geral.

\section{COMUNICAÇÃO E PRODUÇÃO CIENTÍFICA}

A produção científica pode ser considerada o cerne da ciência, é através deste processo que a comunicação se realiza e se conhece a ciência. Entendendo-se a produção científica como sinônimo de "produção intelectual, [...] acadêmica, [...] do conhecimento" (NORONHA; KIYOTANI; JUANES, 2003, p. 140). A produção científica disseminada em periódicos científicos é de suma importância para o se fazer ciência no âmbito acadêmico, 
fazendo do artigo um veículo de disseminação da informação científica, além de ser considerado como modelo de avaliações no sentido acadêmico e governamental.

Sobre a produção científica comunicada e a sua validação pela comunidade científica, ou seja, o reconhecimento pelos pares, ressalta-se a necessidade da publicação dos artigos em periódicos científicos através dos canais formais de comunicação científica. Noronha e Maricato (2008, p. 117) afirmam que "é reconhecido o fato de a pesquisa científica ser condição básica para a evolução do ser humano, provocando e ampliando permanentemente a evolução do conhecimento".

A produção científica como aponta Meadows (1999), está relacionada com a quantidade e a qualidade do que é produzido. Em se tratando de periódicos científicos, há diferenciações entre as áreas do conhecimento, segundo o mesmo autor, a área das ciências humanas prefere comunicar suas pesquisas através de livros, diferentemente da área de ciências da saúde que preferem artigos científicos, o que interfere na produtividade entre pesquisadores dessas duas áreas, quando analisado a produtividade científica através da quantidade de artigos públicos.

O artigo científico "é um exercício de articulação das teorias estabelecidas e reconhecidas pela academia" (SANTOS, 1997, p. 34), é nele que o pesquisador deposita a sua produção, o seu estudo. O artigo se torna o braço direito da produção, para posterior comunicação e disseminação das pesquisas científicas, e é em sua publicação que seu conhecimento fica armazenado.

Vale ressaltar a diferenciação que alguns autores apontam sobre publicação e comunicação científica. Weitzel (2006) nos aponta que a publicação científica se dá através do livro e do artigo científico, é a parte formal do processo, a parte escrita. Já a comunicação científica se torna mais abrangente, pois envolve o processo informal, a oralidade, através de leituras, dos colégios invisíveis, entre outros.

Sendo que a comunicação científica formal tem sua disseminação através da publicação de livros e artigos científicos, apresentações de trabalhos e palestras, publicações de anais de eventos etc. Entretanto, a diferenciação entre publicação e comunicação científica informal/formal, não é o foco desta pesquisa, já a comunicação científica que nos interessa é a formal, compreendendo os artigos publicados pela revista Biblos.

A pesquisa se torna uma maneira dos seres humanos saciarem as suas curiosidades, criarem e desenvolverem serviços e produtos visando o coletivo e a sociedade. No qual, para Curty e Boccato (2005, p. 95), “a socialização da informação vem contribuir para o avanço de 
estudos e pesquisas, indo ao encontro das necessidades do pesquisador científico e da comunidade", tendo a pesquisa, sempre um caráter social, econômico, político, cultural e/ou tecnológico.

Segundo Garvey (apud MIRANDA; PEREIRA, 1996, p. 375), a comunicação científica pode ser entendida como:

O conjunto de atividades associadas à produção, disseminação e uso da informação, desde o momento em que o cientista concebe uma idéia para pesquisar, até que a informação acerca dos resultados seja aceita como constituinte do conhecimento científico.

Sendo que a comunicação científica formal, tem como exemplos de seus canais de disseminação da informação "um livro, um artigo de periódico, uma comunicação em congresso, uma dissertação, tese", dentre outros suportes, não só o impresso. (OHIRA, 1998, p. 66). Corroborando com este pensamento, Silva, Menezes e Pinheiro (2003) nos afirmam que "um resultado de pesquisa só ganha importância e só passa a existir após sua publicação, sua divulgação nos canais formais de comunicação científica".

O periódico científico é caracterizado como um veículo

que cumpre funções de registro oficial público da informação mediante a reconstituição de um sistema de editor-avaliador e de um arquivo público - fonte para o saber científico. (MIRANDA; PEREIRA, 1996, p. 376).

Souza (1992) nos aponta uma série que quesitos caracterizadores dos periódicos, como publicações editadas em fascículos, periodização regular, colaboração de vários autores, corpo avaliativo para aceitação dos artigos, entre outros.

O periódico científico tem as suas principais funções na disseminação e no armazenamento das produções científicas comunicadas. No caso da revista Biblos, essas funções se sobressaem de duas maneiras: no formato impresso e o eletrônico, proporcionando acesso aberto aos artigos publicados. O formato eletrônico da revista é organizado pelo Sistema Eletrônico de Editoração de Revista (SEER), que "é um software desenvolvido para a construção e gestão de uma publicação periódica eletrônica" (IBICT, 2010), visando maior agilidade no processo editorial e economia de recursos, através dos padrões internacionais adotados pelo gerenciador.

A produção e a comunicação devem ser entendidas como parte de um processo, não como um todo, já que o objetivo de se produzir é a comunidade científica, o seu aceite por seus pares (NORONHA; MARICATO, 2008), assim como propiciar desenvolvimento social. Segundo Curty e Boccato (2005, p. 95), a comunicação científica visa "favorecer a geração e a disseminação de conhecimentos", pois é nas comunidades científicas (os pares) que se dá o 
reconhecimento da relevância de um estudo, como nos aponta Maia (2006, p. 44), sendo "através da comunicação dos resultados de pesquisa é que os pesquisadores obtêm credibilidade, asseguram a autoria, e proporcionam o debate sobre o resultado de pesquisas, achados e descobertas".

\section{REVISTA BIBLOS}

A FURG, ainda enquanto Fundação Universidade do Rio Grande, lança na década de 70, diversos periódicos institucionais, entre eles a Revista do Departamento de Biblioteconomia e História e a Revista Júris, nos quais serviram de "projeção da universidade no país e no exterior, [...] assumiram o papel de vitrine das atividades de ensino, pesquisa e extensão aqui desenvolvida [...]” (NUNES, 2004, p. 56).

As publicações científicas reafirmavam o compromisso da FURG em promover e estimular a pesquisa em seus diversos níveis de ensino, como afirma seu Regimento Geral (1978) e seu Estatuto (1998). Weitzel (2006, p. 52), nos diz que a revista científica é o "principal marco da constituição da estrutura da comunicação científica, pois surgiu da necessidade genuína de trocas de experiências científicas dos cientistas".

O periódico do Instituto de Ciências Humanas e da Informação (ICHI) da FURG, iniciou suas atividades no segundo semestre de 1978, com o título "Revista do Departamento de Biblioteconomia e História”, tendo a professora Carmem Helena Braz Mirco, então chefe do Departamento de Biblioteconomia e História. Para Mirco $(1978$, p. 7) a publicação da revista resulta "na busca de um auto-aperfeiçoamento e formação contínua" do corpo docente da universidade.

A Revista do Departamento de Biblioteconomia e História teve sete fascículos, distribuídos em quatro volumes, de 1978 a 1983. Com 37 artigos publicados, autores de diversas regiões do Brasil, inclusive do exterior e as áreas de publicações balanceadas (diversificação dos artigos com temáticas ligadas à Biblioteconomia e a História). Em seus sete fascículos, a revista teve periodicidade irregular devido a questões orçamentárias e a falta de colaboradores.

Em 1985, a revista passa a se chamar de Biblos: revista do Departamento de Biblioteconomia e História, apesar de manter os mesmos padrões de publicação e corpo editorial da extinta denominação, começando a numeração de seus fascículos do volume um, 
número um. Com periodização ainda de forma irregular, tendo agora um dos possíveis fatores, a federalização da instituição em 1987, a revista conquista em 1992 a sua publicação anual, se estendendo até 2005, a partir do qual torna-se semestral, mantendo-se até 2009.

Com 31 anos de história e 32 fascículos publicados, a Revista de Biblioteconomia e História, fez gerações de pesquisadores comunicarem suas pesquisas ao longo dos 392 artigos publicados. A história desse periódico nos remete a história da própria instituição, que "por intermédio das atividades de ensino, pesquisa e extensão, as universidades se voltam para a criação, a produção de conhecimento, e a busca do saber" (OHIRA, 1998, p. 66).

\section{ESTUDOS BIBLIOMÉTRICOS}

O procedimento metodológico utilizado na pesquisa foi à análise bibliométrica da revista Biblos, em um total de 32 fascículos entre 1978 e 2009. Para a análise foram coletados os seguintes dados: ano, número do fascículo, autores, sexo dos autores, títulos dos artigos, titulação dos autores, área do artigo, contatos (dado que aparece a partir de 1997) e se há resumo e palavras-chave nos artigos. Os dados coletados foram tabulados em planilhas do Excel $^{\dagger}$, tendo em vista uma melhor organização e visualização das informações.

Para as áreas dos artigos publicados, seguiu-se a classificação da CAPES, através da certificação Qualis, sistema composto por um conjunto de procedimentos que visam aferir a produtividade e qualidade dos periódicos e dos programas de pós-graduação no Brasil. Este sistema estipula conceitos aos periódicos segundo as suas áreas de abrangência, os conceitos são A1 (o mais elevado), A2, B1, B2, B3, B4, B5 e C (conceito com peso zero).

A revista Biblos está dividida em cinco grandes áreas e conceitos diferentes, que são: História (B4), Interdisciplinar (B4), Letras/Linguística (B4), Geografia (B5) e a área de Educação (C). A área da Ciência da Informação se enquadra na grande área denominada de Ciências Sociais Aplicadas I, no qual não consta na classificação da CAPES para a revista Biblos, sendo que a área Ciência da Informação foi enquadrada em alguma outra área diferente na classificação da revista.

Para análise dos dados da pesquisa, se dividiu os 392 artigos que compõem os 32 fascículos da revista Biblos das seguintes áreas segundo os critérios da CAPES: História (e áreas como Arqueologia, Antropologia, Sociologia e Filosofia), Letras/Linguistica, Geografia,

\footnotetext{
${ }^{\dagger}$ O Excel é uma planilha eletrônica para tabulação de dados do pacote Office no sistema operacional Windows.
} 
Ciências Sociais Aplicadas I (no qual se enquadra a Ciência da Informação), Educação e Outros.

Por se tratar de um estudo bibliométrico, a pesquisa utilizou-se de métodos estatísticos para a análise dos dados, tais como: número de artigos e autores no geral, por artigo, por nomenclatura das revistas, número de autores por artigo, percentual das áreas e seus quantitativos de publicações, dentre outras análises que serão apresentadas a seguir. Os estudos bibliométricos "tentam quantificar, descrever e prognosticar o processo de comunicação escrita" (GUEDES; BORSCHIVER, 2009, p. 2), seja através de livros, revistas, seus artigos, autores etc.

Por bibliometria se entende o estudo quantitativo da informação, como nos aponta Foresti (1990, p. 53), caracterizando-a como "uma área extensa da Ciência da Informação e abrange todos os estudos que procuram quantificar os processos da comunicação escrita, aplicando métodos numéricos específicos". Segundo Araújo (2006, p. 12) a Bibliometria é a "técnica quantitativa e estatística de medição dos índices de produção e disseminação do conhecimento científico [...]".

Ainda sobre o método da bibliometria para a análise de dados, Guedes e Borschiver (2009, p. 15), sustentam que "a Bibliometria é uma ferramenta estatística que permite mapear e gerar diferentes indicadores de tratamento e gestão da informação e do conhecimento [...]". Pritchard (1969 apud GUEDES; BORSCHIVER, 2009, p. 3), afirma que a bibliometria compreende "todos os estudos que tentam quantificar os processos de comunicação escrita" e nos "permitem traçar um perfil do mundo científico" (NORONHA; MARICATO, 2008, p. 117).

Sobre os estudos métricos aplicados à ciência, há além da bibliometria, a cientometria (ou cienciometria), infometria (ou informetria) e a webmetria (ou webometria). Resumidamente, a cientomatria mensura o desenvolvimento e o crescimento da atividade científica (SANTOS; KOBASHI, 2009), a infometria estuda a recuperação da informação através de palavras, documentos, textos, fontes ou bases de dados (BUFREM; PRATES, 2005), e a webmetria a organização e uso de sites na internet (NORONHA; MARICATO, 2008).

A bibliometria possui leis que regem a sua aplicabilidade, entre as principais leis se destacam a Lei de Lokta, a Lei de Bradford e a Lei de Zipf. A Lei de Lokta se refere à produtividade dos autores, em estudos que visam mensurar a produção científica partindo-se da premissa que poucos autores produzem muito e muitos autores produzem pouco. Já a Lei 
de Bradforf relaciona a relevância dos periódicos em determinada área, assim como o surgimento e desenvolvimento de determinadas linhas de pesquisas. E a Lei de Zipf estuda a frequência de palavras em textos, como em livros ou artigos científicos.

\section{A PRODUÇÃO CIENTÍFICA NA REVISTA BIBLOS}

\subsection{Autores}

A pesquisa revelou um total de 496 autorias no período pesquisado entre 1978 e 2009, sendo destes 282 autores diferentes, ou seja, descontando os autores com mais de um artigo publicado. A titulação foi analisada levando-se em consideração às 496 autorias, tendo em vista analisar cada artigo em sua particularidade e cada autor no momento de sua publicação, independente da modificação de titulação acadêmica posterior à publicação na revista.

Para análise da pesquisa, os autores foram divididos nos seguintes níveis de titulação: graduando, graduado, especialista, mestrando, mestre, doutorando, doutor e sem identificação (s.i.), utilizado quando o artigo não apresentar informações sobre seu(s) autor(es). Tendo em vista que a revista não apresentou em seus 31 anos de publicação uma padronização única que contivesses informações completas sobre os autores, os resumos e as palavras chave dos artigos, obtendo-se dificuldades na identificação de alguns itens para a pesquisa.

Alguns artigos, não possuem informação referente à titulação de seus autores, entretanto, em trabalhos publicados anteriormente na revista, há a informação do "doutorado" para o mesmo autor(a), a partir dessa informação utilizou-se a titulação anterior para posteriores publicações, tendo em vista que o título de doutor não se perde e não há título acima deste para análise da pesquisa (há a titulação de pós-doutorado e de livre-docência, entretanto não foram categorizados nesta pesquisa). O mesmo não pode ocorrer em outras titulações, já que se um autor, por exemplo, possui o título de mestre em publicação do ano 2000, não se assegura que continue com o mesmo titulo em uma publicação sem identificação quanto à titulação do ano 2004, pois poderá se manter mestre, ser doutorando ou doutor.

A titulação mais evidente entre os autores está o título de doutor(a), no qual aparece 135 vezes ou 27,18\%, seguindo por ordenação de titulação os doutorandos(as) com 35 ou $7,07 \%$, dos mestres com 70 ou $14,11 \%$ e os mestrandos com 31 ou $6,25 \%$. O que demarca uma maior produção e comunicação científica pelos autores que estão/estiveram em 
programas de pós-graduação, sendo os doutores em sua maioria docentes pesquisadores, no qual a produção de conhecimento está ligada ao gosto pessoal pela ciência e a atividade em que exerce.

Os graduados(as) e graduandos(as), perfazem um importante percentual de autorias, sendo de 75 autores ou $15,11 \%$ e 59 autores ou $11,89 \%$, respectivamente, o que demonstra uma procura por parte daqueles que estão na ou possuem graduação de comunicar suas pesquisas, seja pelo interesse do diálogo científico com seus pares, pela necessidade de reconhecimento acadêmico e/ou elaboração de um currículo mais competitivo para o mercado de trabalho. Os autores que não possuem informações sobre a sua titulação representam 81 ou $16,32 \%$ dos casos e os especialistas compreendem 10 autores ou 2,02\%.

Para identificar os autores com maior produtividade na revista Biblos, utilizou-se como critério àqueles autores que possuem três ou mais artigos publicados, tendo somado 28 autores. Destes, 21 autores possuem/possuíram vínculo de docência na FURG, 6 possuem/possuíram vínculo de estudante em algum momento de sua vida acadêmica na universidade (FURG) e um autor professor universitário de outra instituição de ensino do interior do Estado do Rio Grande do Sul. Dos 21 autores mais produtivos na revista Biblos que possuem/possuíram vínculo de docência na universidade (FURG), dez se encontram ativos na função (considerando os autores que estão em período de afastamento, seja cedidos a outros órgãos ou para doutorado).

Entre os autores mais produtivos encontram-se professores doutores ligados a FURG, no qual o indicaremos como AP (autor produtivo), como o prof. Dr. AP1, com 42 artigos publicados entre 1990 e 2009; prof. Dr. AP2, com 36 artigos publicados entre 1992 e 2009; prof. Dr. AP3, com 14 artigos publicados entre 1992 e 2009, sendo professores ligados à área de História da universidade e em plena atividade docente. O grande número de publicações pode ser explicado por Cavalcanti et al. (2000, p. 19), que nos diz que há "uma forte pressão para publicar, uma vez que a progressão na carreira nas universidades e institutos de pesquisa têm como base de avaliação a produtividade científica".

Entre autores ligados à área de Ciência da Informação, aparece o prof. Dr. AP4, com 11 artigos publicados entre 1985 e 2008, atualmente em situação de afastamento da universidade; e a prof ${ }^{a}$ Ms. AP5, com 10 artigos publicados entre 1979 e 2002, a professora está aposentada, ambos docentes da FURG, aparecendo em $4^{\circ}$ e $5^{\circ}$ lugares respectivamente, na listagem dos autores mais produtivos. Essa grande produtividade dos cinco autores com mais artigo publicados na Biblos reflete o que Medeiros (1986 apud OHIRA, 1998, p. 67) 
salienta, "o interesse pessoal reflete uma postura do profissional que, independentemente de suas obrigações quanto ao regime de trabalho ou outras implicações, realiza trabalhos que vão ao encontro de suas satisfações".

O título de doutor(a) aparece em dez dos 28 autores mais produtivos, sendo todos docentes da FURG. Entre alguns autores identifica-se uma evolução de suas titulações, como por exemplo, o prof. AP4 que têm artigos publicados enquanto graduando da FURG (1985, v. 1), especialista (1990, v. 3), mestre (1996, v. 8, dois artigos), doutorando (1997, v. 9) e doutor (de 2002 com o v. 11 a 2008 com o v. $22, n^{\circ} .1$, totalizando seis artigos publicados no referido período), sendo desde 1990, docente da mesma instituição no qual realizou sua graduação. Essa evolução demonstra um histórico do autor com a revista e a instituição, o que caracteriza também uma evolução na escrita do autor e de seu interesse em manter publicações no periódico.

Levando em consideração os 282 autores diferentes que publicaram na revista Biblos, identificou-se que 157 autores do sexo feminino, perfazendo um total de 55,67\%. As autorias do sexo masculino correspondem a 117 autores ou 41,49\%. Verificou-se que em 8 autorias $(2,84 \%)$ não foi possível identificar o sexo, tendo em vista serem nomes estrangeiros e/ou estarem apenas com as iniciais. Entre os 28 autores mais produtivos da revista, 15 são do sexo feminino e 13 do sexo masculino. No âmbito de análise da revista Biblos, observa-se uma maior publicação de autores do sexo feminino, o que pode ser evidenciado nos autores com maior produtividade, assim como com o total de autores na revista.

Um ponto relevante é a falta de padronização nas publicações da revista, segundo as "Diretrizes para os Autores", no site da revista, o item 4 revela como devem ser submetidos os artigos “ "[...] o nome do autor deverão constar dados especificando a atividade que exerce, a instituição em que trabalha e titulação acadêmica, além de endereço completo para correspondência e telefone." (BIBLOS, 2010). Entretanto, em 81 autorias não houve a possibilidade de informação em relação à titulação (16,33\%) e em $76(15,32 \%)$ a instituição a qual estão vinculados, e apenas 37 autores (7,45\%) dos autores possuem contato de e-mail, predominantemente nos últimos fascículos publicados pela revista.

A pesquisa ainda identificou o número de co-autorias nos artigos publicados. Dos 392 artigos analisados, $330(84,18 \%)$ possui apenas uma autoria (escrito por um único autor). Já os artigos com co-autoria perfaz um total geral de $15,82 \%$ dos artigos. A tabela 1 nos mostra o percentual de co-autores. 


\begin{tabular}{lc}
\hline \multicolumn{1}{c}{ Autoria e co-autoria } & $\mathbf{\%}$ \\
\hline Apenas um autor & $84,18 \%$ \\
\hline Um autor e um co-autor & $8,93 \%$ \\
\hline Um autor e dois co-autores & $4,85 \%$ \\
\hline Um autor e três co-autores & $1,27 \%$ \\
\hline Um autor e quatro co-autores & $0,51 \%$ \\
\hline Um autor e mais de quatro co-autores & $0,26 \%$ \\
\hline
\end{tabular}

Tabela 1: Distribuição das autorias na revista Biblos

Fonte: própria

\section{2 Áreas}

A partir da identificação das áreas dos artigos publicados na Biblos, observa-se uma massificação de artigos publicados na área de História e uma quase inexistência de artigos das áreas de Geografia e Letras/Linguística. Entre os fatores dessa possível causa está o fato que a revista desde a sua criação pertenceu ao antigo Departamento de Biblioteconomia e História, atual Instituto de Ciências Humanas da Informação, mantendo coordenadores do corpo editorial da área de História, área que sempre contou com um maior número de professores e maior titulação, se comparado com a Biblioteconomia na instituição, sendo que de docentes efetivos atuantes na universidade no ano de 2010, a área de História conta com 10 professores, todos doutores, e a área de Biblioteconomia conta com 6 docentes, sendo apenas dois doutores. O gráfico 1, nos mostra um panorama geral da mensuração das temáticas dos artigos publicados em cada área.

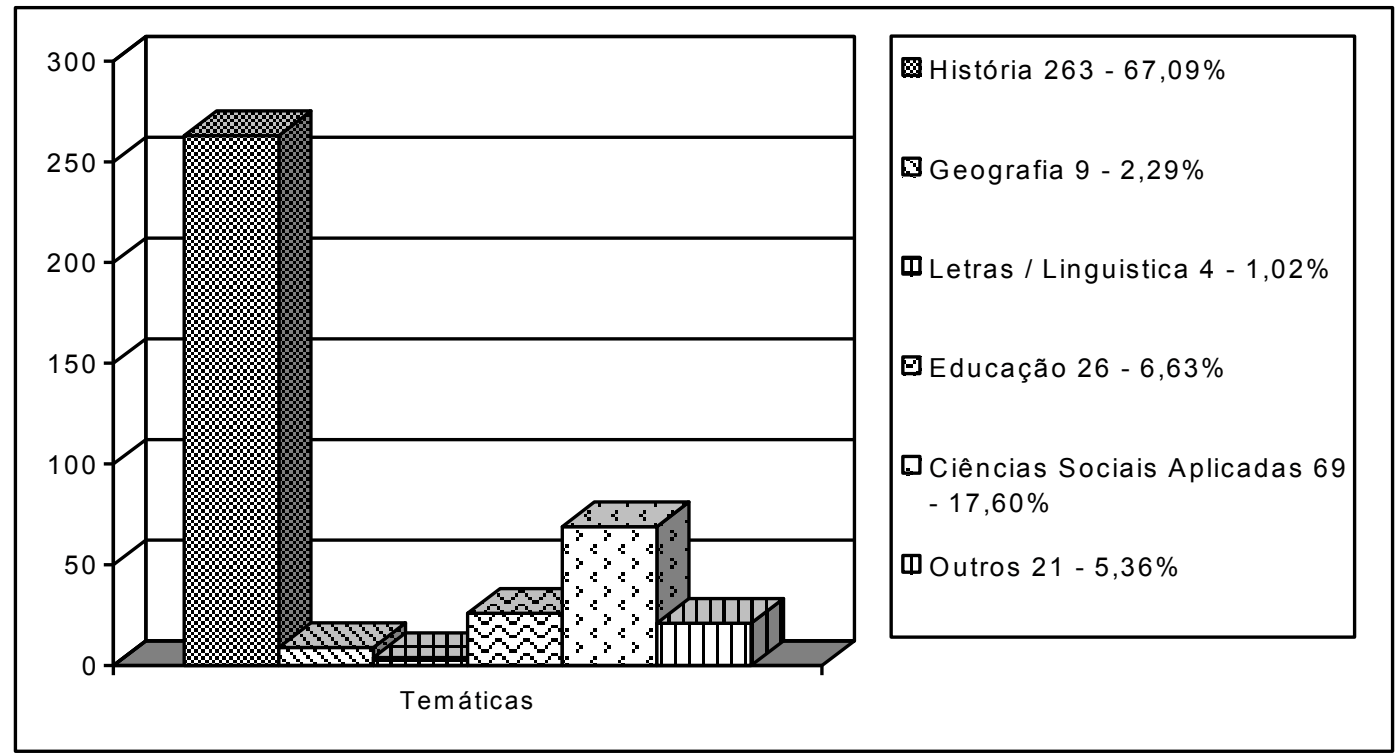

Gráfico 1: Áreas do conhecimento dos artigos publicados pela revista Biblos. Fonte: Elaborada pelo autor. 
$\mathrm{Na}$ grande área denominada de História, encontram-se artigos específicos de cunho historiográfico, assim como artigos das áreas de Arqueologia, Antropologia, Sociologia e Filosofia relacionados ou não com a área da História. A presença dessas áreas correlatas é um fator determinante para o elevado índice de artigos classificados com a área de História. Entre as temáticas mais trabalhadas estão os estudos arqueológicos da região sul-rio-grandense, já os temas mais comunicados da História se destacam os artigos que abordam a história da cidade do Rio Grande e do Estado do Rio Grande do Sul, questões étnicas, a imprensa gaúcha, relações internacionais e as relações políticas, intelectuais, sociais e culturais brasileiras.

A área de Geografia apresenta artigos que abordam questões espaciais relacionados ao desenvolvimento urbano e ao espaço natural na cidade do Rio Grande, assim como relações da evolução demográfica local e o espaço territorial da região platina e romana. A área das Letras e Linguística ocupa um pequeno espaço na revista, com apenas 1,02\% do total, 4 artigos publicados, tendo em suas temáticas análises de obras literárias específicas e a presença da mulher na literatura.

A Educação teve 26 artigos classificados em sua grande área. $\mathrm{O}$ ensino superior, a educação brasileira, o ensino de História e o incentivo a leitura são algumas das temáticas abordadas por essa área, assim como a relação da educação com a cidadania, a racionalidade, o Estado, a História, a ideologia, a globalização e as Tecnologias da Informação e da Comunicação (TIC’s).

A grande área das Ciências Sociais Aplicadas I na revista Biblos se divide entre a Biblioteconomia, a Arquivologia e a Museologia, o tripé formador da Ciência da Informação. As temáticas mais trabalhadas foram às bibliotecas universitárias e escolares, acessibilidade em bibliotecas, automação de unidades de informação, preservação documental, os currículos dos cursos de Biblioteconomia, usuários de informação, fontes de informação, ação cultural em bibliotecas e museus, indexação e recuperação da informação, configuração de web sites, serviço de referência, ética profissional, o perfil do bibliotecário e os relatos de experiência referentes a ações de tratamento técnico em acervos.

Os artigos em que suas temáticas não se encaixavam na proposta de classificação utilizada pela pesquisa, perfazem um total de 21 artigos e foram enquadrados como "Outros". Essas outras temáticas são assuntos que abordavam questões relacionadas a: Administração, Economia, Direito, Políticas Públicas, Comunicação, Artes, entre outras.

Quanto à padronização da revista, a pesquisa teve algumas dificuldades, já que não houve uma normalização dos artigos publicados pela revista Biblos, nem nos fascículos 
pesquisado, nem mesmo uma padronização por exemplar, já que em diversas revistas encontram-se artigos com resumos e palavras, apenas com resumos e artigos sem ambos os quesitos. Observou-se que a utilização do software SEER para editoração eletrônica da revista não amenizou o problema da padronização editorial, sendo que a falta de padronização acompanhou a revista ao longo de sua história. A Tabela 2 apresenta a padronização dos artigos.

\begin{tabular}{lc}
\hline \multicolumn{1}{c}{ Quesitos } & Número de artigos \\
\hline Com resumos e palavras-chave & 215 \\
\hline Com resumos e sem palavras-chave & 104 \\
\hline Sem resumos e palavras-chave & 73 \\
\hline \multicolumn{1}{c}{ Total de artigos } & 392 \\
\hline
\end{tabular}

Tabela 2: Resumos e palavras-chave nos artigos na Biblos.

Fonte: elaborado pelo autor.

\section{CONSIDERAÇÕES FINAIS}

Diante dos resultados levantados pela pesquisa e através da análise dos dados coletados, observa-se um elevado volume de produção científica proporcionada pela revista Biblos. Os 392 artigos publicados ao longo dos 32 fascículos de 1978 e 2009 nos remetem a uma média de cerca de 12,25 artigo por cada nova edição da revista, mesmo de maneira irregular, já que a revista publicou fascículos com 4 artigos e outros fascículos com mais de 20 artigos.

O alto índice de autores da própria instituição é reflexo do desempenho da revista junto ao Qualis da CAPES, no qual entre os critérios estão publicações de autores de outras instituições e corpo editorial diversificado, assim como fator de impacto na comunidade científica, indexação em bases de dados, avaliação conjunta com cursos de pós-graduação etc. Recomenda-se que o corpo editorial seja formado com pesquisadores de outras instituições de ensino e reconhecidos por suas comunidades científicas, este é outro fator determinando para o desempenho na avaliação, já que a revista Biblos, possuía no ano de 2010 seu corpo editorial totalmente composto por pesquisadores da FURG.

O fato de a revista publicar em sua maioria artigo de autores da própria instituição prejudica a sua visibilidade no meio acadêmico. já que a revista se torna pouco conhecida, disseminada e consequentemente, tendo uma baixa procura de autores de outras instituições com interesse em publicar os resultados de suas pesquisas na Biblos. A publicação de artigos 
de autores da FURG pelos avaliadores da própria instituição coloca em debate a avaliação por pares, dita as cegas, da revista. Entretanto, a pesquisa não visou julgar os critérios de avaliação da revista, mas sim levantar pontos relevantes para a análise da produção científica pela revista Biblos.

Os resultados indicam $67,09 \%$ de artigos publicados são da área de História, fato que nos deixa a interrogação se houve um certo desinteresse por pesquisadores da área de Ciência da Informação em publicarem suas pesquisas, levando em conta que originalmente a revista foi criada para publicação dos docentes da FURG e que nesses 31 anos percorridos pela pesquisa, a revista sempre pertenceu ao departamento de Biblioteconomia e História, tendo essas áreas como as principais, essa análise leva em consideração as publicações na revista Biblos, já que os pesquisadores da Ciência da Informação (da instituição e no geral) podem estar publicando suas pesquisas em outros periódicos que não Biblos. Fator que deve ser levando em conta é o número de professores das áreas de História e Biblioteconomia na FURG serem distintos, tendo a área de História um número maior de docentes e com titulação mais elevada, o que talvez não se justifique tendo em vista que a revista aceita artigos de egressos desses cursos, de pesquisadores de outras instituições e artigos de relatos de experiência.

Sobre as temáticas da revista, um ponto interessante é a classificação das áreas segundo o Qualis da CAPES, sendo a revista enquadra-se em áreas como Geografia e Letras/Linguística, sendo que a pesquisa identificou e classificou apenas 9 e 4 artigos em cada área, respectivamente. Deve-se levar em consideração que essa pesquisa realizou a sua classificação, deixando em aberto para discussões a respeito da classificação dos artigos segundo as suas grandes áreas.

A pesquisa mostrou que os doutores e os graduandos são a maioria dos autores da revista. Fator importante pois representam os opostos na escala de titulação estabelecida para está pesquisa, o que demonstra uma abertura da revista no aceite de publicações de autores (ainda) não renomados e/ou reconhecidos por seus pares.

Os autores mais produtivos são os docentes pesquisadores da própria instituição, quer seja pela facilidade na submissão de artigos na revista (conhecimento da revista e/ou conhecimento dos critérios de avaliação), como uma maneira mais próxima de publicar suas pesquisas para a sua comunidade científica no âmbito da própria FURG ou até mesmo por um desconhecimento da revista pelas suas comunidades científicas. A pesquisa ainda revelou que $55,67 \%$ dos autores são do sexo feminino, demonstrando uma maior produção e comunicação 
formal de pesquisas por parte das mulheres, fator que se confirma pelos autores mais produtivos da revista também serem do sexo feminino, sendo estes 15 e 13 do sexo masculino.

Frente ao momento de transformação da revista Biblos, sugere-se a alteração/implementação de alguns quesitos na revista, tais como: padronização dos artigos e dos fascículos publicados; a inclusão do endereço eletrônico como critério para publicação da revista; corpo editorial diversificado, com pesquisadores de outras instituições, para possibilitar uma maior confiabilidade à avaliação dos artigos; maior divulgação da revista nos programas de pós-graduação da área, assim como nos cursos de graduação em Ciência da Informação; divulgação com maior antecedência dos prazos de submissão de artigos a revista; a inserção no sistema SEER dos fascículos impressos que ainda não está no meio digital; e, a revisão dos fascículos que já estão no sistema pois possuem erros de digitação, como nomes de autores e títulos dos artigos publicados, o que pode ser comprovado pela edição impressa dos volumes.

A pesquisa revelou um perfil dos autores que publicaram na revista Biblos, assim como uma identificação das áreas e das temáticas mais trabalhadas pelos autores nas páginas da revista. Através da análise métrica foi possível realizar e analisar os dados levantados, tendo o trabalho alcançado seus objetivos iniciais. O estudo deixa em aberto para futuros trabalhos que utilizem os estudos bibliométricos para novas análises da produção científica em periódicos institucionais.

\section{REFERÊNCIAS}

ARÁUJO, Carlos Alberto. Bibliometria: evolução histórica e questões atuais. Em Questão, Porto Alegre, v. 12, n. 1, p. 11-32, jan./jun. 2006. Disponível em: $<$ http://www.seer.ufrgs.br/index.php/EmQuestao/article/view/16/5>. Acesso em: 22 maio 2010 .

BIBLOS: revista do Instituto de Ciências Humanas e da Informação. Disponível em: $<$ http://www.seer.furg.br/ojs/index.php/biblos>. Acesso em: 30 set. 2010.

BIBLOS: revista do Instituto de Ciências Humanas e da Informação. Seção de Diretrizes para autores.

$<$ http://www.seer.furg.br/ojs/index.php/biblos/about/submissions\#authorGuidelines>. Acesso em 27 set. 2010.

BUFREM, Leilah; PRATES, Yara. O saber científico registrado e as práticas de mensuração da informação. Ciência da Informação, Brasília, v. 34, n. 2, p. 9-25, maio/ago. 2005 
Disponível em: <http://revista.ibict.br/index.php/ciinf/article/view/682/587>. Acesso em: 21 maio 2010.

CAVALCANTI, Ilce Gonçalves Milet et al. Análise comparativa da produção científica entre as áreas sociais e tecnológicas. In: Seminário Nacional de Bibliotecas Universitárias, $10^{\circ}$, 2000, Florianópolis, SC. Anais... Florianópolis, 2000. Disponível em: $<$ http://snbu.bvs.br/snbu2000/docs/pt/doc/t131.doc>. Acesso em 30 set. 2010.

CURTY, Marlene Gonçalves; BOCCATO, Vera Regina Casari. O artigo científico como forma de comunicação do conhecimento na área de Ciência da Informação. Perspectivas em Ciência da Informação, Belo Horizonte, v.10 n.1, p. 94-107, jan./jun. 2005. Disponível em: $<$ http://www.eci.ufmg.br/pcionline/index.php/pci/article/viewFile/305/108>. Acesso em 04 maio 2010.

FORESTI, Nóris Almeida Bethonico. Contribuição das revistas brasileiras de Biblioteconomia e Ciência da Informação enquanto fonte de referência para a pesquisa. Ciência da Informação, Brasília, v. 19, n. 1, p. 53-71, jan./jun. 1990. Disponível em: $<$ http://revista.ibict.br/index.php/ciinf/article/view/1259/900>. Acesso em: 24 maio 2010.

FUNDAÇÃO UNIVERSIDADE DO RIO GRANDE. Regimento Geral. Rio Grande: Ed. FURG, 1978.

FUNDAÇÃO UNIVERSIDADE FEDERAL DO RIO GRANDE. Estatuto. Rio Grande: Ed. FURG, [1999].

GUEDES, Vânia L.; BORSCHIVER, Suzana. Bibliometria: uma ferramenta estatística para a gestão da informação e do conhecimento, em sistema de informação, de comunicação e de avaliação cientifica e tecnológica. Encontro Nacional de Ensino e Pesquisa em Informação, 12. . Anais... $\quad$ Salvador, 2009. Disponível em: $<$ http://www.cinform.ufba.br/vi_anais/docs/VaniaLSGuedes.pdf>. Acesso em 21 maio 2010.

INSTITUTO BRASILEIRO DE INFORMAÇÃO EM CIÊNCIA E TECNOLOGIA - IBICT. Portal do Sistema Eletrônico de Editoração de Revistas. Disponível em: $<$ http://seer.ibict.br/>. Acesso em: 10 out. 2010.

MAIA, Maria de Fátima Santos. A produção e o uso de informação em saúde: estudo bibliométrico da área de epidemiologia. 2006. 119 p. (Dissertação Mestrado Comunicação e Informação) - Programa de Pós-Graduação em Comunicação e Informação, Universidade Federal do Rio Grande do Sul - UFRGS, Porto Alegre, 2006.

MIRANDA, Dely Bezerra de.; PEREIRA, Maria de Nazaré Freitas. O periódico cientifico como um veículo de comunicação: uma revisão de literatura. Ciência da Informação, Brasília, v. 25, n. 3, p. 375-382, set./dez. 1996. Disponível em: $<$ http://revista.ibict.br/ciinf/index.php/ciinf/article/view/462/421>. Acesso em: 04 maio 2010.

MEADOWS, Arthur Jack. A comunicação científica. Brasília: Briquet de Lemos, 1999.

MIRCO, Carmem Helena Braz. Apresentação. Revista do Departamento de Biblioteconomia e História. Rio Grande, v. 1, n. 1, jul./dez., 1978. 
NORONHA, Daisy Pires; KIYOTANI, Normanda Miranda; JUANES, Ivone A. Soares. Produção científica de docentes da área de comunicação. Informação \& Sociedade: Estudos, João Pessoa, v. 13, n. 1, p. 139-157, jan./jun. 2003. Disponível em: $<$ http://www.ies.ufpb.br/ojs2/index.php/ies/article/view/124/1579>. Acesso em: 02 out. 2010.

.; MARICATO, João de Melo. Estudos métricos da informação: primeiras aproximações. Encontros Bibli: Revista Eletrônica de Biblioteconomia e Ciência da Informação, Florianópolis, n. esp., $1^{\text {o }}$ sem. 2008. Disponível em: $<$ http://www.periodicos.ufsc.br/index.php/eb/article/view/1137/1594>. Acesso em: 12 jun. 2010.

NUNES, Cláudio Omar Iahnke. Ciências Sociais Aplicadas. In: ALVES, Francisco das Neves (Org.). Fundação Universidade Federal do Rio Grande: 35 anos a serviço da comunidade. Rio Grande: Ed. FURG, 2004.

OHIRA, Maria Lourdes Blatt. Porque Fazer pesquisa na Universidade? Revista ACB: Biblioteconomia em Santa Catarina, Florianópolis, v.3, n.3, 1998. Disponível em: $<$ http://revista.acbsc.org.br/index.php/racb/article/view/329/389> Acesso em: 30 abr. 2010.

SANTOS, Raimundo Nonato Macedo dos; KOBASHI, Nair Yumiko. Bibliometria, Cientometria, Infometria: conceitos e aplicações. Pesquisa brasileira em Ciência da Informação, Brasília, v.2, n.1, p.155-172, jan./dez. 2009. Disponível: $<$ http://inseer.ibict.br/ancib/index.php/tpbci/article/view/21/43>. Acesso em: 30 abr. 2010.

SANTOS, Rejane Silva Alves dos. A produção científica favorável à humanização dos novos tempos. Informação \& Sociedade: Estudos, João Pessoa, v.7, n.1, p.34-41, jan./dez. 1997. Disponível em: <http://www.ies.ufpb.br/ojs2/index.php/ies/article/view/353/1600>. Acesso em: 02 maio 2010.

SILVA, Edna Lúcia da; MENEZES, Estera Muszkat; PINHEIRO, Líliane Vieira. Avaliação da produtividade científica dos pesquisadores da área de ciências humanas e sociais aplicadas. Informação \& Sociedade: Estudos, João Pessoa, v. 13, n. 2, p. 193-222, jul./dez. 2003. Disponível em: <http://www.ies.ufpb.br/ojs2/index.php/ies/article/view/97/1567>. Acesso em: 02 maio 2010.

SOUZA, Denise H. Farias. Publicações periódicas: processos técnicos, circulação e disseminação seletiva da informação. Belém: Ed. UFPA, 1992.

WEBQUALIS. Disponível em: <http:/qualis.capes.gov.br/webqualis/>. Acesso em 29 set. 2010 .

WEITZEL, Simone da Rocha. O papel dos repositórios Institucionais e temáticos na estrutura da produção científica. Em Questão, Porto Alegre, v. 12, n. 1, p. 51-71, jan./jun. 2006. Disponível em: <http://www.seer.ufrgs.br/index.php/EmQuestao/article/view/19/7>. Acesso em: 22 maio 2010. 